\title{
ANTONIO GARCÍA Y BELLIDOY SU ÉPOCA: UNA POSIBLE LECTURA ${ }^{\prime}$
}

\author{
POR \\ RICARDO OLMOS \\ Departamento de Historia Antigua y Arqueologia, CHE, CSIC, Madrid
}

Presentar esta convocatoria cientifica que hoy nos reune en torno a la figura del profesor Antonio Garcia y Bellido es para mi un honor a la vez que un reto y un riesgo. Pues el objetivo principal de esta jornada es el tratar de acercarnos a través de las propuestas de diversos especialistas y de la discusión final a la labor gigantesca del que fue un investigador único y, junto con él, a la de toda una época crucial de la arqueología española, la que nos lleva de la década de los años 1930 a los inicios de la década de 1970.

Pero este año, además de que sea placentera una convocatoria cientifica como la presente en la que pretendemos escucharnos y establecer un diálogo, además, digo, es esta reunión ante todo, para algunos de los aquí estamos, un deber. Con Garcia y Bellido, tanto sus alumnos más directos como los que no lo fuimos más que incidentalmente, tenemos contraida una enorme deuda. En García y Bellido se perfila y desarrolla una significativa visión de la arqueologia histórica del mundo antiguo que marcará época y abrirá camino y dará pauta a múltiples indagaciones posteriores. Pero además fue García y Bellido el creador de un importante cauce científico con el que quiso aglutinar gran parte de la arqueologia clásica - prerromana y romana - en España a lo largo prácticamente de tres décadas: los años 40 a 70. Este deseo aglutinador se realizó por medio de una institución como lo fue el antiguo Instituto de Arqueología Rodrigo Caro, diseñado y sostenido

\footnotetext{
' Se reproduce, con pequeñas variantes, el texto de presentación de la Reunión Científica del Dia Antonio Garcia y Bellido dedicada este año al análisis del tema "Cincuenta años de Arqueologia ibérican, Departamento de Historia Antigua y Arqueologia "Rodrigo Caro", miércoles 9 de febrero de 1994.
}

fundamentalmente por él y su autoridad cientifica desde inicios de los años $50^{2}$. Pero de todo ello, y del instrumento científico que fue sobre todo la Revista Archivo Español de Arqueologia como foro de discusión, nacional e internacional, de la arqueología clásica en España nos hablará enseguida en pormenor el profesor Javier Arce ${ }^{3}$.

Que hoy se celebre en el actual Centro de Estudios Históricos que ha absorbido aquellos pequeños institutos especializados como lo fue, prácticamente durante treinta y cinco años el Rodrigo Caro es, digo, un deber así como un acto de sincero agradecimiento a su fundador y promotor. Estaremos o no de acuerdo con unas u otras, con muchas o con pocas, de las formulaciones cientificas de Garcia y Bellido. Estarán o no superadas tales o cuales propuestas y modos de enfocar la historia. Pero somos deudores y herederos de la tradición histórica de nuestros predecesores y hoy, en nuestro caso, la investigación del mundo antiguo en sus vertientes principalmente histórica y arqueológica lo es en una gran medida de la figura de Garcia y Bellido. Creo que

\footnotetext{
Cf. A. Garcia y Bellido, AEspA, $X X V 1951$ pp. 161 ss. Cf. los comentarios de R. Olmos, Esbozo de una historia del departamento. El antiguo Instituto de Arqueologia "Rodrigo Caro" en $A E \operatorname{spA}, 64,1991$, pp. 352-4, dentro de una reseña más amplia sobre el actual Departamento.

Sobre la figura cientifica y humana de Antonio Garcia y Bellido ef. la comunicación de J. Arce sobre A. Garcia y Bellido. Garcia y Bellido y los comienzos de la historia antigua en España, Congreso Internacional «Historiografia de la Arqueologia y la Historia Antigua en España (siglos xwm-xx) 1989. Madrid, Ministerio de Cultura, 1991, págs. 209-211. Asimismo, $\mathrm{M}^{*}$ Paz Garcia-Bellido, Prólogo a A. Garcia y Bellido, España y los españoles hace dos mil años segun la Geografia de Estrabón. $10^{\prime \prime}$ ed. Madrid 1993, pp. 10-44.
} 
un modo de expresar ese agradecimiento es tratar de situar, de valorar y de comprender, en su perspectiva historica adecuada, uno de los aspectos de la actividad cientifica de ese hombre que ejerció por completo la imvestigación como vocación. Antonio Garcia y Bellido. Hoy nos ocupará en especial su visión del mundo ibérico, sus aportaciones a esta faceta de la arqueología prerromana en España.

FI presente no es autosuficiente ni absoluto y no se puede explicar encerrado en si mismo, sin acudir al pasado. El historiador debe recuperar esa memoria del tiempo pretérito que en la arqueologia además puede materializarse en las cosas. El pasado es siempre un estímulo de reflexión y la misma investigación no debe liberarse de una critica de sí misma, de un autoanálisis. Uno de los diversos caminos de reflexión es proyectarse en el espejo de los que nos antecedieron. Esta búsqueda, si es profunda, puede ayudar a explicar en ocasiones aspectos del presente. Nuestra situación actual más o menos buena o mala, según se quiera ésta leer-con nuestras virtudes y limitaciones, con nuestros aciertos y desaciertos cientificos, debe implicar también esta reflexión historiográfica de nuestro pasado inmediato.

Creo que esta reunión no pretende ser nostálgica sino científica. Lo que no implica que no sea afectiva. Estamos aprendiendo todos a compartir el afecto y el respeto con la crítica. La razón y la pasión pueden ir unidas. La generación de los que andamos ahora entre los 40 y 50 años, olvidada inconscientemente de la historia inmediata, con demasiada frecuencia disoció una y otra.

Durante muchas décadas no se ejercitó en España la reflexión historiográfica. Un Pio Baroja historiador del siglo romántico en los años 30 notaba ya con su aguda perspicacia «esa extraña falta de curiosidad de los españoles del siglo xıx por la historia viva" ${ }^{4}$. "España - diría después Antonio de Obregón en 1934 - es uno de los pueblos donde más sucesos importantes se han desarrollado sin dejar rastron ${ }^{5}$.

Pero en estos últimos años se está recuperando el hábito perdido de la memoria histórica. Era una paradoja que historiadores y arqueólogos, quienes precisamente nos dedicamos a este oficio del pasado, no nos aplicáramos el cuento y la receta a nosotros mismos. En este sentido la arqueología española ha sido, creo, poco reflexiva desde esta meditación

Pio Baroja, Siluetas romanticas o hiografias extravaganles, Madrid, Espasa Calpe, 1934.

- Antonio de Obregón, recensión al libro citado de Pio Baroja. en Revista de Occidente, $n " 132$, junio de 1934, pp. 335-344, especialmente p. 339. de la historiografia. Apenas nos hemos ocupado de nuestra historia mas directa y proxima, de nuestra investigacion inmediata. Desde luego, mucho menos que los colegas alemanes que han escrito, por ejemplo, sus Archäologische Bildnisse, esas biografias y valoraciones de los principales arqueólogos de lengua alemana desde Winckelmann hasta los que florecieron a mediados de este siglo $\mathrm{xx}^{\circ}$. Algunos, como Ludwig Curtius, llegaron a escribir en relatos tan entrañables como ricos en ideas, sus recuerdos. las vivencias que tuvieron o que les llegaron de sus profesores y colegas en arqueología, los Lehenserinnerungen como les llamaba, digo, Curtius?. Por no detenernos en sus "Nachrufe", esas evocaciones funerarias que, al sabor clásico del recuerdo entrañable hacia el compañero desaparecido, se une la valoración de la obra cientifica del investigador en su paso por esta vida. No digamos la arqueologia británica, en un pais tan devoto de la National Biography como Inglaterra: podria hacerse una cierta historiografia de la arqueologia nada superficial, como en general de la ciencia inglesa, por los obituarios de periódicos como el Times. Nos es dado conocer bien la historia de la cátedra de arqueologia clásica de Oxford, de aquellos que fueron transmitiéndose el titulo de Lincoln Professor, desde Sir Arthur Evans al ya hoy próximo a jubilarse John Boardman pasando por figuras como Percy Gardner, John Davidson Beazley, Bernard Ashmole o Martin Robertson ${ }^{x}$. La biografia que de ellos se ha hecho - en gran parte es autobiografia, reflexión interna que parte de la misma cátedra como institución - se muestra critica: lo que hicieron y lo que no hicieron, las opciones que desecharon y las que potenciaron con la carga ideológica y cientifica que unas u otras implicaron, en fin su responsabilidad positiva o negativa en ese colectivo que es, en el curso de tantas generaciones de «escolares», la arqueología oxoniana. Ellos saben que, históricamente, a su vez serán objeto de la critica por parte de las generaciones sucesivas. El historiador mismo se convierte así en historia. Pero en España, digo, ese ejercicio se ha desarrollado poco y hoy puede ayudarnos tal vez esta reunión para avanzar algo más en un camino aún prácticamente

\footnotetext{
"Archäologische Bildnisse. Porträts und Kurzbiogruphic'n von klassischen Archäologen deutscher Sprache. (eds. R. Lullies y W. Schiering), Mainz, 1988.

${ }^{7}$ L. Curtius, Deutsche und antike Welt. Lebenserinnerungen. Stuttgart, 1950.

* John Boardman, 100 Years of Classical Archaeology in Oxford, Beazley and Oxford. Lectures delivered at Wolfson Co. Ilege, Oxford, on 28 June 1985 (ed. by D.C. Kurtz), Oxford, 1985, pp. 43-55. Cf. el precedente, 100 años antes, de Percy Gardner, Classical Archaeology at Oxford. Oxford, 1890.
} 
por desbrozar como es la historia de nuestro propio oficio de historiadores.

Hemos elegido este año como hilo conductor de nuestra reunión la visión del mundo ibérico, una parcela importante en la actividad de Garcia y Bellido y del antiguo Instituto Rodrigo (aro. Un tema además importante y de actualidad en el campo de nuestra arqueologia española: se apuntan en estos años búsquedas y propuestas nuevas. La última sintesis de Arturo Ruiz y Manuel Molinos, Los Iheros. Análisis arqueológico de un proceso historico", presenta algunas de las posibilidades de la nuevas búsquedas en un espacio y en un tiempo ibérico dialéctico. Pues bien, el planteamieneto de hace unos cincuenta años, época ya de plena madurez de Garcia y Bellido, fue clave para la fijación de la arqueologia del periodo ibérico. Como hoy, aquella época presentó con claridad sus problemas y propuso sus soluciones. Unas han perdurado y son válidas. Otras, no. Más atrás aún en el tiempo, cuando García y Bellido se introduce en la ciencia en los inicios de los años 30 , este campo mantenía unos limites aún oscuros y bastante mal definidos. Existía, por el contrario, una importante historiografia romana con sus ámbitos, cronológico y temático, precisos. De lo ibérico apenas se tenía nada por seguro. Ni siquiera el nombre. Es decir, incluso el mismo nombre fluctuaba. Sin querer ahora pecar de nominalistas hemos de admitir que el nombre es un cauce fundamental de las ideas: si no es un espejo de ellas, "un vestido transparente del pensamiento" como pensaba Unamuno ${ }^{10}$, no se puede negar que el lenguaje si interviene en su estructuración y ordenación. Y así, vemos cómo la denominación ibérica abarcaba desde comienzos de siglo ámbitos tan heterogéneos como las manifestaciones del neolítico o del ámbito tartesio. Algunos querían ver entonces en lo ibérico lo prehistórico. El nombre se reservaba sobre todo para lo neolitico. Cuando al final de los años 20, Garcia y Bellido, aún como investigador bisoño se asoma a la arqueología, Gómez Moreno trataba de imponer a las manifestaciones que hoy consideramos ibéricas el nombre de hispánicas, como expresión de una alta cultura histórica, nacional. Juan Cabré, una o dos décadas anterior a Bellido, y con aquél muchos otros vacilan y en ocasiones ceden al señuelo de este nombre, como el de hispánico, tan sobrecargado de connotaciones

\footnotetext{
${ }^{9}$ Edit. crítica, Barcelona, 1993. Cf. la recensión de Lorenzo Abad, La «historia» de los Iberos, en Arqrítica. 6. 1993. pp. 13-14.

${ }^{10} \mathrm{M}$. de Unamuno, En torno al casticismo, Madrid, Col. Austral, reimpr. 1991, p. 35, abajo.
}

ideológicas ". Las oscilaciones del nombre se mantendrán - creo que por el indudable carisma patriarcal de Don Manuel - hasta incluso después de la guerra, si bien ahora ya de forma más esporádica. Lo veremos luego, más detenidamente, cuando me toque hablar de la cerámica y aludamos al Corpus l'asorum Hispanorum ${ }^{12}$. Baste aqui decir que en Garcia y Bellido se afirma plenamente la nomenclatura ibérica aceptada años atrás por Bosch Gimpera. Entendió pues y usó ya lo ibérico prácticamente en la misma acepción histórica nuestra. Bosch (jimpera y Garcia y Bellido son dos viejos pilares fundamentales de nuestra moderna arqueología ibérica.

El siglo $x ı x$ apenas conocia la arqueologia ibérica. Cuando en los primeros años 80 se descubre la bicha de Balazote no se sabe ni cómo llamarla ni dónde encuadrarla históricamente: se la sitúa bien como producción caldea bien como obra palacial bizantina ${ }^{13}$. Las dos propuestas valen y encuentran entonces respaldo cientifico. Pues prácticamente no existia la categoria de lo ibérico cuando una u otra se formulan. Y de este modo, a las Damas del Cerro de los Santos, descubiertas poco antes, se las denominó mártires visigodas. Así, Amador de los Rios, a finales de siglo. Lo ibérico constituia, pues, una categoria borrosa, imprecisa. Urgía una rigida taxonomia. Entre estas afirmaciones disparatadas y los inicios de la producción científica de García y Bellido apenas median dos generaciones de investigadores. Sus predecesores más inmediatos - como un ya lejano Pierre Paris Pongero, Manuel Gómez Moreno, A. Schulten y el mismo José Ramón Mélida y aquellos otros que alcanzaron su cénit con unas dos décadas de antelación a García y Bellido como Bosch Gimpera y Rhys Carpenter - todos ellos paulatinamente $y$ de un modo $u$ otro tratan de aproximarse a la realidad ibérica en el espacio y en el tiempo, es decir, en la historia. La época de Garcia y Bellido,

" (ff. Juan Cabré, Arquitectura hispánica. El sepulero de Toya, Archivo Expañol de Arte y Arqueologia, 1. 1925, p. 73: enecesitamos de dicho nombre (iberismo) para aplicarlo al arte de nuestro primitivo neolitico persistente muchos siglos con fijeza en la región del E:bro, o sea la lberia propia, donde no se manifiesta dicha otra cultura». Seria preferible llamarle «periodo hispánico a este con que se inicia la arqueologia histórica españolan. Se puede seguir la ambigüedad o fluctuación de la denominación (ibérica, hispánica) durante, al menos, las dos décadas siguientes en las páginas de $A E s p A A$ y luego $A E s p A$.

12 Hice un análisis del fenómeno histórico del Corpus Vasorum Hispanorum en $\mathrm{mi}$ articulo, $\mathrm{E} 1$ "Corpus vasorum Hispanorum», setenta años después: pasado, presente y futuro del gran proyecto internacional de la cerámica antigua, AEspA, vol. 62 . 1989. pp. 292-303.

"Rodrigo Amador de los Rios, Espuña. Sus monumentos y. artes. Su naturaleza e historia. Murcia y Albacete. Barcelona, 1889 , pp. $720 \mathrm{ss}$. 
empezando por algunos coetáneos suyos más viejos como Juan Cabré y por otros más jóvenes como Domingo Fletcher, fue precisamente crucial para las definiciones y para el enmarque histórico de lo ibérico, más o menos como lo entendemos hoy. Bellido vivió inmerso en estos problemas de precisión. Recordemos su famosa tesis romana sobre la Dama de Elche - que hoy nadie acepta - argumentada desde la arqueologia y desde las fuentes textuales antiguas ${ }^{14}$. La situación, el enmarque histórico del mundo ibérico era entonces prioritario. Sólo por ello hoy puede serlo el análisis de su proceso diálectico, territorial y social o los primeros ensayos de una caracterización semiótica de su universo imaginario. Podemos hoy jugar mejor con las metáforas pues estamos algo mejor asentados en la realidad.

Seguramente a algunos les parecerá hoy superfluo, ingenuo o excesivo el afán tipológico y definidor de aquella época. Entonces era necesario. Los limites se necesitaban precisar también internamente. Se precisaba clasificar el mundo ibérico. García y Bellido será, si, un intérprete pero también, como hombre de aquella época, fué un clasificador. Bien es cierto que Bellido trascendió la tipologia para hacer historia que era lo que más le interesaba. No se quedó nunca en aquélla.

La tipologia es clasificación, es taxonomía e implica un contacto directo con la materialidad de los documentos. Entonces, en los años 30 y 40, el arqueólogo se relacionaba directamente con los documentos. Por de pronto en aquel originario Centro de Estudios Históricos era prioritario ficharlos. Lo ibérico, como lo púnico, lo griego o lo romano, se integraba en aquel fichero de arte antiguo, vinculado a la filosofía del patrimonio histórico y monumental del Centro. A Bellido se le encargó, antes de la guerra, de la parcela antigua de este fichero, lo que le permitió un contacto y familiaridad con los objetos y con los dibujos y fotografias de los objetos. Uno de los primeros frutos sería su librito «Los hallazgos griegos en España» ${ }^{15}$. Seguirian, después de la guerra, muchos otros en esta linea, como sus «Esculturas romanas de España y Portugal ${ }^{16}$. Se partía, simplemente, del documento, escrito o material. La hermeneútica era sencilla. Constituia una especie de adecuación primaria entre el investigador y el objeto. A ello se añadía, en el caso de García y Bellido, la inmensa erudición de las fuentes

\footnotetext{
14 A. García y Bellido, La Dama de Elche y el conjunto de piezas arqueológicas reingresadas a España en 1941. Madrid 1943.

is Madrid, Centro de Estudios Históricos, 1936.

it Madrid, CSIC, 1949, 2 vols.
}

literarias. Pero también con ésta la relación era directa. Hoy interponemos más el discurso. Entre el investigador y los documentos se ha introducido el filtro de la hermeneútica cientifica, de la contextualidad, de la duda. Desconfiamos de las palabras de las nuestras y las de los antiguos - y de que éstas nos ofrezcan una relación directa por un lado con el pensamiento y por el otro con las cosas. Somos en ello, dramáticamente, deudores indiscutibles de nuestra época. Posiblemente estamos intercalando más que nunca los textos nuestros y los de otros investigadores entre el pasado y nuestra lectura que en ocasiones no es, no puede ser tan directa como entonces. Bellido, al contrario, creía leer con mayor inmediatez, sin tantos artilugios, lo ibérico o lo romano. ¿Qué vamos a tratar de leer hoy?, ¿también lo ibérico?, ¿o será nuestra interpretación de la visión de Bellido y de su época de lo ibérico? De este modo hoy más que nunca sentimos que la realidad se nos escapa. Pero, paradójicamente, también puede resultar más compleja y matizada. Tal vez no podamos ya evitarlo.

La visión arqueológica de García y Bellido fue enormemente creadora. Era una creatividad desbordante en los más variados campos del pasado. Sólo uno de ellos era el mundo ibérico. Sería ingenuo pretender comparar hoy la creatividad de la investigación actual con la de la época de Bellido. Son parámetros diferentes ${ }^{17}$. La vitalidad científica de entonces pudo conllevar que no fuera necesario pararse y calibrar los límites de los postulados, las barreras que nos impone el pensamiento. Garcia y Bellido, un pensador pragmático, no tuvo grandes formulaciones epistemológicas. Le guió un instinto primordial y el sentido común. Sin mayores preocupaciones se sirvió de las categorías historiográficas de la época ${ }^{18}$. Hoy debemos aplicar una parte de la creatividad a esta reflexión marginal. Un objetivo de esta jornada que aqui nos reune podría ser el detenernos, siquiera un instante, en esta investigación de prisas que nos caracteriza. Compartir con la reflexión de todos la semilla ibérica de Garcia y Bellido es también proyectar al futuro la investigación de lo ibérico. Y reflexionar sobre lo que dijeron

${ }^{17}$ En este punto consistiria mi esencial discrepancia con el texto - tan motivador y sugestivo, por otro lado- de Javier Arce que se ofrece también en las páginas de la revista, un Javier Arce al que me he permitido calificar en estas jornadas - con la carga de respeto y afecto profundo que ello implica como de verdadero tábano socrático.

18 Por ejemplo, incorporó sin molestias las tesis continuistas, desde la Hispania antigua, de las raices históricas de España, que se aceptaban ya en el siglo xıx y que propiciaría finalmente con la polémica Claudio Sánchez Albornoz. 
nuestros predecesores - y sobre todo, entender por qué lo dijeron, es decir, situarlos en su limitación histórica - no debe implicar una decadencia de pensamiento arqueológico. Como si, no teniendo otras cosas más novedosas que decir, nos refugiáramos en las formulaciones de los otros. No: este ejercicio de la critica es parte integrante de la historia.

Los temas aqui propuestos se dividen, al modo tradicional, en parcelas temáticas - escultura, arquitectura, urbanismo, cerámica, fuentes históricasprecedidas por un análisis historiográfico sobre la personalidad científica y la obra de Garcia y Bellido en el antiguo Rodrigo Caro ${ }^{19}$. Se trata asi de re-

Iv Estos son los ponentes y temas de la jornada cientifica que figuran en el programa: Javier Arce, "El Instituto español de Arqueologia Rodrigo Caro y la Revista Archivo Español de Arqueologia en la concepción de Antonio Garcia Bellidon; Martin Almagro, «De arquitectura ibérica»; Michael Blech, "La visión de la escultura ibérica, ayer y hoyn: Lorenzo Abad y Manuel Bendala, "La urbanistica del mundo ibérico: las nuevas perspectivas»; Fernando Quesada, "Los mercenarios ibéricos y la concepción histórica en la obra de Garcia y Bellidon: Ricardo Olmos, "Problemas historiográficos de cerámica ibérica e iconografian. Este último trabajo será publicado en Revista de estudios Ihericos, I. 1994. coger los principales aspectos que trató este autor en relación con el mundo ibérico. Su distribución responde pues, en gran medida, al viejo modelo de la investigación. Podrian, efectivamente, haber sido otras las propuestas pero creo que asi tenemos una repartición tradicional, sencilla y útil. Nuestro discurso $y$, sobre todo, la discusión que esperamos surja de todos los participantes servirán para entrelazar los aspectos parciales en la dialéctica de la globalidad.

Quedan, por último, unas breves palabras de acogida. Debo indicar que, siguiendo el espiritu de la tradición de estas jornadas, nos encontramos ante una reunión austera, sin la fluidez económica a que nos podian tener acostumbrados otros fastos cientificos. Por ello, en nombre del Departamento de Historia Antigua y Arqueologia del Centro de Estudios Históricos quiero agradecer muy cordialmente a todos - investigadores, familiares y amigos - su participación y su presencia. Especialmente quiero agradecer la colaboración desinteresada de los colegas que en estos dias han dedicado su tiempo y esfuerzo en preparar su comunicación y en ofrecernos hoy su valiosa aportación cientifica. Muchas gracias a todos.

\title{
GARCÍA Y BELLIDO Y EL INSTITUTO RODRIGO CARO
}

\author{
POR
}

\author{
JAVIER ARCE \\ Escuela Española de Historia y Arqueologia del C.S.I.C. Roma
}

En 1951 Antonio García y Bellido publicaba en Archivo Español de Arqueología una especie de manifiesto sobre lo que entendía él que deberia ser el recién creado Departamento o Instituto de Arqueología Rodrigo Caro. El motivo era, simplemente, que en ese año lo que era una sección del Instituto Diego Velázquez de Historia del Arte, se hizo independiente como Instituto de Prehistoria y Arqueología.

Considero este escrito de García Bellido el documento básico para comprender la idea que tenía sobre su Instituto y para entender en qué principios fundamentaba su acción y su futuro. En esta ocasión que se me brinda de recordar al gran investigador, arqueólogo e historiador, me limitaré a estudiar este texto que contiene todavía muchísimos puntos e ideas válidas, sugerencias y recomenda- ciones que invitan a la reflexión y que permite, sobre todo, contrastar lo que él se propuso y lo que hizo y el desarrollo posterior del Instituto.

Se plantea aquí una cuestión de principio, esto es, en qué medida y por qué hemos de seguir o continuar el espíritu del, llamémoslo así, «padre fundador", en qué medida debemos o no debemos considerar importante o necesaria la continuidad. Creo que podriamos estar de acuerdo en que mantener las líneas maestras y esenciales que han guiado e impulsado un centro de investigación o una revista, constituye la caracteristica definitoria y de identificación de la historia, la línea y la coherencia de este centro. Constituye su propia definición. En el curso del tiempo sobrevienen modificaciones y adaptaciones a los contextos y exigencias que van surgiendo; 